Article

\title{
CopA Protects Streptococcus suis against Copper Toxicity
}

\author{
Chengkun Zheng ${ }^{1,2,3, * \mathbb{D}}$, Mengdie Jia ${ }^{1,2}$, Tianyu Lu ${ }^{1,2}$, Miaomiao Gao ${ }^{1,2}$ and Lingzhi Li ${ }^{1,2}$ \\ 1 Joint International Research Laboratory of Agriculture and Agri-Product Safety, The Ministry of Education \\ of China, Yangzhou University, Yangzhou 225009, China; jiamengdie@163.com (M.J.); \\ 18252734942@163.com (T.L.); miaomiaogao1@163.com (M.G.); 18762314176@163.com (L.L.) \\ 2 Jiangsu Key Laboratory of Zoonosis, Yangzhou University, Yangzhou 225009, China \\ 3 State Key Laboratory of Agricultural Microbiology, Huazhong Agricultural University, Wuhan 430070, China \\ * Correspondence: zhengchengkun@yzu.edu.cn; Tel.: +86-1520-527-9658
}

Received: 1 May 2019; Accepted: 16 June 2019; Published: 18 June 2019

check for updates

\begin{abstract}
Streptococcus suis is a zoonotic pathogen that causes great economic losses to the swine industry and severe threats to public health. A better understanding of its physiology would contribute to the control of its infections. Although copper is an essential micronutrient for life, it is toxic to cells when present in excessive amounts. Herein, we provide evidence that CopA is required for S. suis resistance to copper toxicity. Quantitative PCR analysis showed that copA expression was specifically induced by copper. Growth curve analyses and spot dilution assays showed that the $\triangle$ copA mutant was defective in media supplemented with elevated concentrations of copper. Spot dilution assays also revealed that CopA protected S. suis against the copper-induced bactericidal effect. Using inductively coupled plasma-optical emission spectroscopy, we demonstrated that the role of CopA in copper resistance was mediated by copper efflux. Collectively, our data indicated that CopA protects S. suis against the copper-induced bactericidal effect via copper efflux.
\end{abstract}

Keywords: CopA; Streptococcus suis; copper toxicity; copper resistance

\section{Introduction}

As an important zoonotic pathogen, Streptococcus suis not only causes great economic losses to the swine industry worldwide but is also responsible for severe threats to public health. It leads to meningitis, septicemia, pneumonia, endocarditis, and arthritis in pigs, and is associated with meningitis, septicemia, and streptococcal toxic shock-like syndrome in humans [1-3]. Of the 29 serotypes (1-19, $21,23-25,27-31$, and $1 / 2$ ) proposed on the basis of the pathogen's capsular polysaccharides, S. suis serotype 2 (S. suis 2 ) is generally considered to be the most virulent and the most prevalent in both pigs and humans [4-9]. As of 31 December 2013, there have been at least 1642 human cases of S. suis infection, with the majority reported in Vietnam, Thailand, and China [10]. In particular, two large outbreaks of human S. suis infections in China (in 1998 and 2005, respectively) have changed the opinion that this pathogen only causes sporadic human cases [2,9]. S. suis is a persistent threat both to the swine industry and to public health; therefore, a better understanding of the physiology of this agent will undoubtedly contribute to the control of its infections.

Copper, an essential micronutrient for life, functions as a cofactor for a wide variety of enzymes that are involved in various cellular processes [11]. However, an excessive amount of $\mathrm{Cu}$ is toxic to cells [11]. Cu has been applied as an antimicrobial agent for thousands of years [12]. Furthermore, the host can utilize $\mathrm{Cu}$ toxicity as a mechanism to control bacterial infections [13]. For example, guinea pigs respond to Mycobacterium tuberculosis infection by increasing the concentration of $\mathrm{Cu}$ in the lung lesions [14]. Moreover, mutation of the Cu-responsive genes results in attenuated virulence in 
many pathogens $[12,13,15]$. As a countermeasure, bacteria have evolved several mechanisms to avoid $\mathrm{Cu}$ toxicity, including $\mathrm{Cu}$ export, $\mathrm{Cu}$ sequestration, and $\mathrm{Cu}(\mathrm{I})$ oxidation [12]. Among the numerous $\mathrm{Cu}$ exporters that have been described, the $\mathrm{Cu}$ exporting $\mathrm{P}_{1 \mathrm{~B}}$-type ATPases are universally present in bacteria [13]. The most extensively studied Cu-responsive system in Gram-positive bacteria is the cop $Y Z A B$ operon of Enterococcus hirae, which encodes two P-type ATPases [16]. Similar Cu-responsive operons have been identified in several streptococcal species, such as Streptococcus mutans $[17,18]$, Streptococcus gordonii [19], Streptococcus pneumoniae [20], and Streptococcus pyogenes [21]. Nevertheless, no such operon or other $\mathrm{Cu}$-responsive mechanism has been reported in S. suis.

In a previous study, we identified two Spx regulators (viz. SpxA1 and SpxA2) in S. suis, and found that SpxA1 modulates oxidative stress tolerance and virulence [22]. Although the $\operatorname{cop} A$ gene (encoding a Cu-transporting ATPase) is significantly down-regulated in the $\triangle$ spxA1 mutant, it appears to play no role in oxidative stress tolerance and virulence in S. suis [23]. Analysis of the genetic organization of copA in S. suis revealed that this gene is not arranged in an operon, making it quite distinct from its homologues in certain species of streptococci [17-21]. Thus, we surmised whether CopA could confer protection against $\mathrm{Cu}$ toxicity in S. suis.

In this study, we examined the role of CopA in $\mathrm{Cu}$ tolerance in S. suis. Our findings revealed that expression of the copA gene was specifically induced in response to $\mathrm{Cu}$. The $\triangle \operatorname{cop} A$ mutant exhibited growth inhibition under conditions of excess $\mathrm{Cu}$. Furthermore, we demonstrated that CopA was required for $\mathrm{S}$. suis resistance to the $\mathrm{Cu}$-induced bactericidal effect, and the role of CopA in $\mathrm{Cu}$ resistance was mediated by $\mathrm{Cu}$ efflux.

\section{Results}

\subsection{S. suis CopA Is a Homologue of the Copper Efflux System}

In S. suis 2 strain SC19, CopA encoded by the B9H01_RS06680 locus had 54\%, 52\%, and 45\% amino acid sequence identity to CopA from S. mutans, S. pyogenes, and S. pneumoniae, respectively. In S. mutans, S. gordonii, and S. pyogenes, the genes copY (encoding a Cu-responsive transcriptional regulator), $\operatorname{cop} A$, and copZ (encoding a $\mathrm{Cu}$ chaperone protein) form a Cu-responsive operon, cop YAZ (Figure 1) [17-19,21]. In S. pneumoniae, a cupA gene (encoding a hypothetical protein) is present in the operon instead of copZ (Figure 1) [20]. The cop operon of E. hirae consists of four genes that encode CopY, CopZ, CopA, and CopB, respectively (Figure 1) [24]. Unlike the operon organization in these species, the $\operatorname{cop} A$ gene in S. suis is far away from the copY and copZ genes, and these two genes are separated by a gene that encodes a hypothetical protein (Figure 1). Multiple sequence alignment suggested that CopA from prokaryotes shares several conserved motifs (Figure 2). Furthermore, blastn searches revealed that the copA gene was present in all complete S. suis genomes, with $92 \%$ to $100 \%$ nucleotide sequence identity (Table 1), indicating that it is highly conserved among a wide range of S. suis strains.

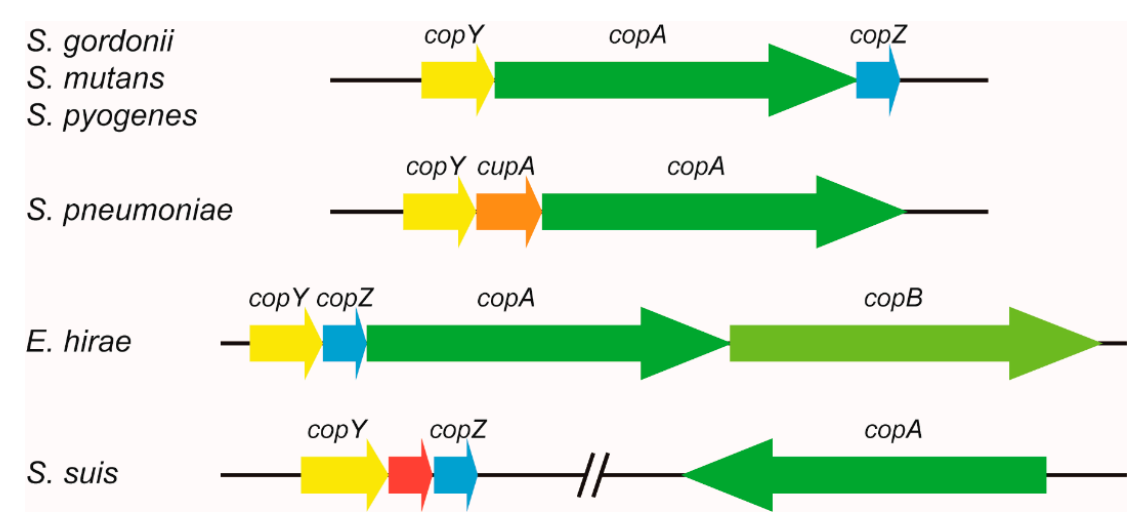

Figure 1. Genetic organization of the cop genes in several streptococci and Enterococcus hirae. In Streptococcus suis, the copY and copZ genes are separated by a gene (the red arrow) that encodes a hypothetical protein. Arrows indicate the direction of transcription. 


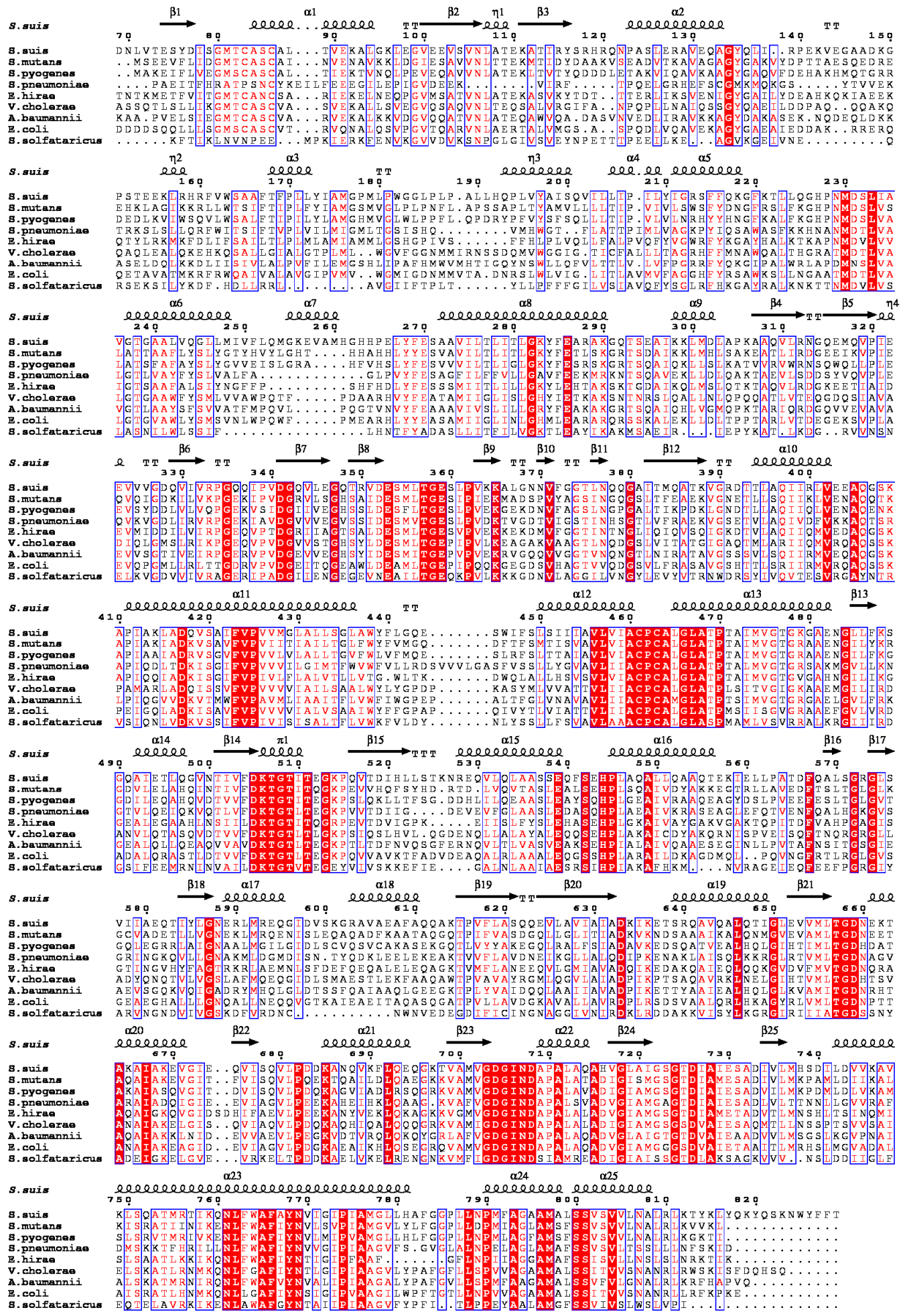

Figure 2. Multiple sequence alignments of CopA homologues. Identical residues are in white letters with red background; similar residues are in red letters with white background. The modelled structure of Streptococcus suis CopA is shown on the top. $\alpha$ indicates $\alpha$-helix; $\beta$ indicates $\beta$-sheet; $\eta$ indicates coil; and T indicates turn. The GenBank accession numbers are as follows: S. suis, WP_012775225.1; Streptococcus mutans, NP_720873.1; Streptococcus pyogenes, AAZ52023.1; Streptococcus pneumoniae, WP_000136284.1; E. hirae, WP_131773415.1; Vibrio cholerae, NP_231846.1; Acinetobacter baumannii, AKA32424.1; Escherichia coli, NP_415017.1; and Sulfolobus solfataricus, WP_009988559.1. 
Table 1. Sequence identity of the copA gene in S. suis.

\begin{tabular}{|c|c|c|}
\hline S. suis Strains & Locus Tag & Gene Sequence Identity (\%) ${ }^{1}$ \\
\hline LSM102 & A9494_06425 & 100 \\
\hline SC19 & B9H01_06680 & 100 \\
\hline SS2-1 & BVD85_06510 & 100 \\
\hline ZY05719 & ZY05719_06610 & 100 \\
\hline A7 & SSUA7_1228 & 100 \\
\hline $\mathrm{P} 1 / 7$ & SSU1214 & 100 \\
\hline BM407 & SSUBM407_0575 & 100 \\
\hline SC84 & SSUSC84_1247 & 100 \\
\hline S735 & - & 99 \\
\hline GZ1 & SSGZ1_1230 & 99 \\
\hline SS12 & SSU12_1279 & 99 \\
\hline 05ZYH33 & SSU05_1385 & 99 \\
\hline 98НАН33 & SSU98_1400 & 99 \\
\hline SH0104 & - & 97 \\
\hline HA0609 & CR542_03955 & 97 \\
\hline $90-1330$ & AN924_03380 & 97 \\
\hline NSUI060 & APQ97_02765 & 97 \\
\hline NSUI002 & AA105_03890 & 97 \\
\hline 05HAS68 & HAS68_0686 & 97 \\
\hline YB51 & YB51_2960 & 97 \\
\hline D9 & SSUD9_0599 & 97 \\
\hline ST3 & SSUST3_0597 & 97 \\
\hline CS100322 & CR541_06915 & 97 \\
\hline $\mathrm{T} 15$ & T15_0568 & 97 \\
\hline SC070731 & NJAUSS_1288 & 97 \\
\hline JS14 & SSUJS14_1360 & 97 \\
\hline ST1 & SSUST1_0574 & 96 \\
\hline ISU2812 & A7J09_03980 & 96 \\
\hline SH1510 & DP111_07130 & 96 \\
\hline GZ0565 & BFP66_02780 & 95 \\
\hline DN13 & A6M16_02880 & 95 \\
\hline 6407 & ID09_03115 & 95 \\
\hline TL13 & TL13_0615 & 95 \\
\hline CZ130302 & CVO91_03355 & 95 \\
\hline HN105 & DF184_07440 & 95 \\
\hline HN136 & CWM22_09360 & 95 \\
\hline SRD478 & A7J08_03040 & 92 \\
\hline 1081 & BKM67_07590 & 93 \\
\hline 0061 & BKM66_07040 & 93 \\
\hline D12 & SSUD12_0568 & 92 \\
\hline HA1003 & DP112_07660 & 92 \\
\hline AH681 & CWI26_08525 & 92 \\
\hline
\end{tabular}

${ }^{1}$ Gene sequence identity is compared with the copA gene of SC19 strain.

\subsection{S. suis Up-regulates copA Expression in Response to Copper}

To determine the involvement of $S$. suis CopA in the bacterial resistance to metal toxicity, the copA expression levels in the presence of elevated levels of $\mathrm{Cu}$ or various other metals were tested. The copA expression level of strain SC19 was approximately 530-fold higher in the medium supplemented with $0.5 \mathrm{mM} \mathrm{Cu}$ than in the control (Figure 3). In contrast, no significant difference in cop $A$ expression was detected when the SC19 strain was treated with other metals (Figure 3). Hence, copA expression was induced specifically in response to $\mathrm{Cu}$. 


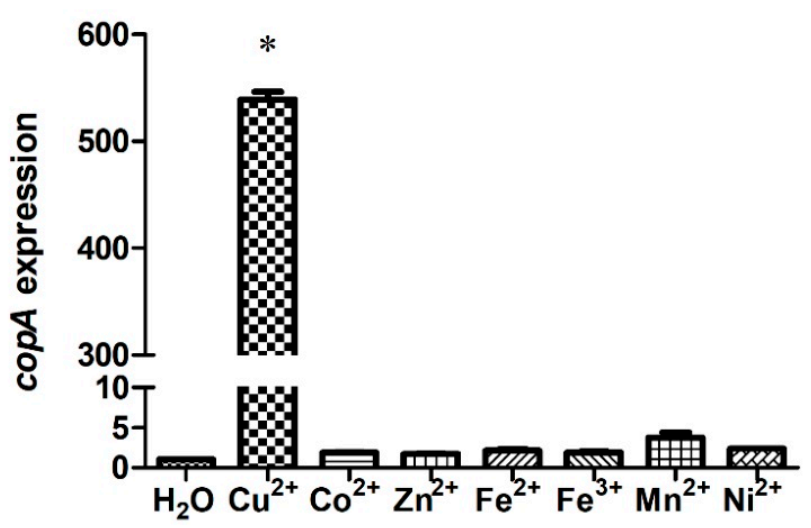

Figure 3. $\operatorname{cop} A$ expression is up-regulated in response to copper. S. suis was grown in the presence of various metals, and the gene expression levels were calculated using the $2^{-\Delta \Delta C T}$ method with $16 \mathrm{~S}$ rRNA as the reference gene. Results represent the means and standard deviations (SD) from three biological replicates. * indicates $p<0.05$.

\subsection{CopA Is Required for Copper Resistance in S. suis}

The wild-type (WT), $\triangle \operatorname{cop} A$, and $\triangle \operatorname{cop} A:: \operatorname{cop} A$ strains were cultured in media supplemented with various concentrations of $\mathrm{Cu}$, and their growth curves were measured to determine the role of CopA in $\mathrm{Cu}$ resistance. As seen in Figure 4A, all three strains showed identical growth in the absence of $\mathrm{Cu}$. However, when supplemented with $\mathrm{Cu}, \triangle \operatorname{cop} A$ clearly exhibited impaired growth compared with the WT and $\triangle \operatorname{cop} A$ ::copA strains (Figure 4B-F). Surprisingly, defective $\triangle$ copA growth was observed in the presence of as little as $0.05 \mathrm{mM} \mathrm{Cu}$ (Figure $4 \mathrm{~B}$ ), and $0.5 \mathrm{mM} \mathrm{Cu}$ almost completely inhibited the mutant strain's growth (Figure 4E).
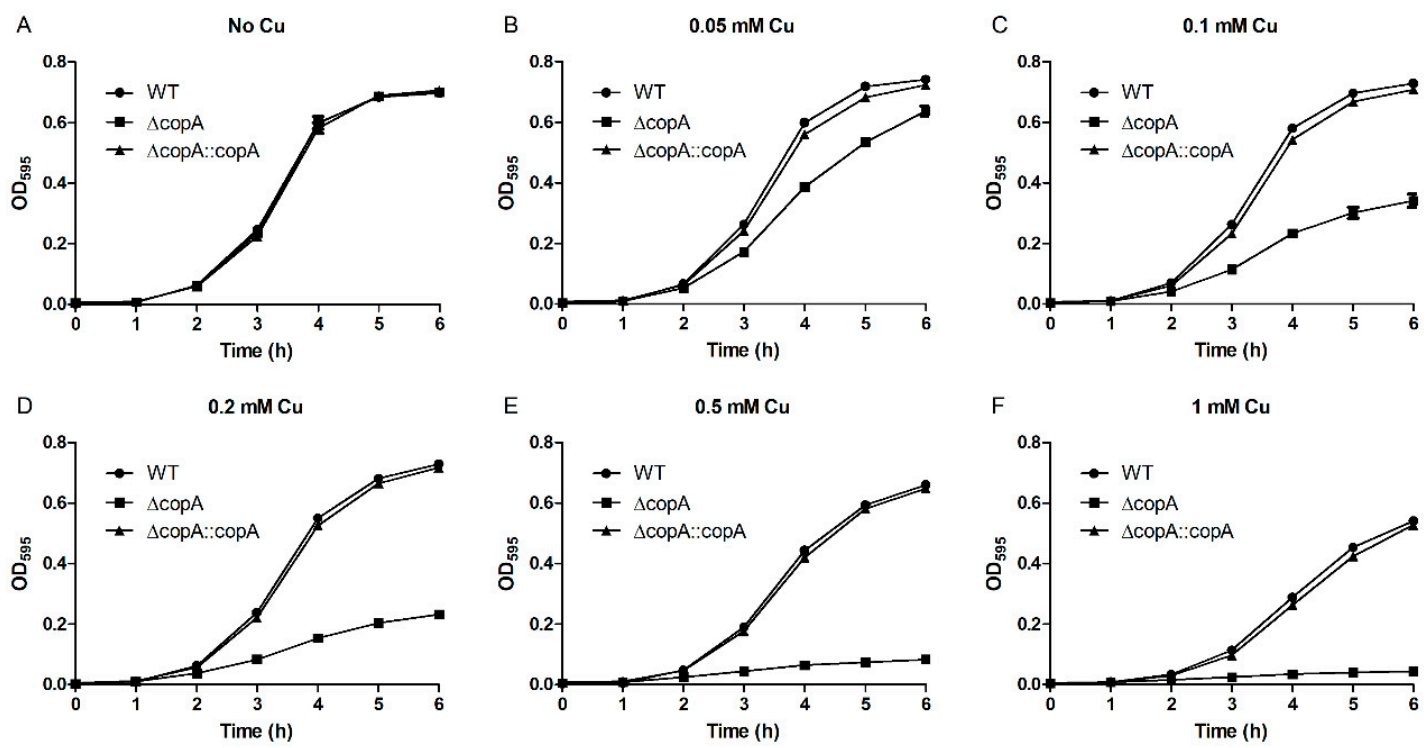

Figure 4. CopA is required for S. suis resistance to copper toxicity in liquid medium. Growth curves of the wildtype (WT), $\triangle \operatorname{cop} A$, and $\triangle \operatorname{cop} A:: \operatorname{cop} A$ strains in the absence (A) and presence of $0.05 \mathrm{mM}(\mathbf{B})$, $0.1 \mathrm{mM}(\mathbf{C}), 0.2 \mathrm{mM}(\mathbf{D}), 0.5 \mathrm{mM}(\mathbf{E})$, and $1 \mathrm{mM}(\mathbf{F}) \mathrm{Cu}$. The data in the graphs are the means and SD from three wells.

The growth defect phenotype of $\triangle c o p A$ under $\mathrm{Cu}$ excess conditions was also observed on agar plates. The WT, $\triangle \operatorname{cop} A$, and $\triangle \operatorname{cop} A:: \operatorname{cop} A$ strains all formed colonies with high efficiency in the absence of $\mathrm{Cu}$ (Figure $5 \mathrm{~A}$ ). In the presence of $\mathrm{Cu}$, however, $\triangle$ cop $A$ clearly exhibited a decreased ability to form colonies compared with the WT and $\triangle \operatorname{cop} A:$ :copA strains (Figure 5B-D). 
A

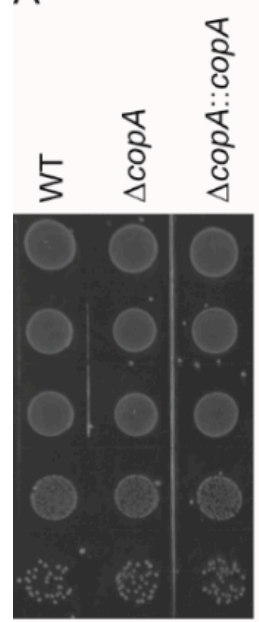

$\mathrm{No} \mathrm{Cu}$
B

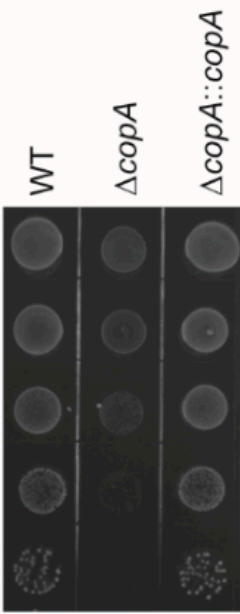

$0.1 \mathrm{mM} \mathrm{Cu}$
C

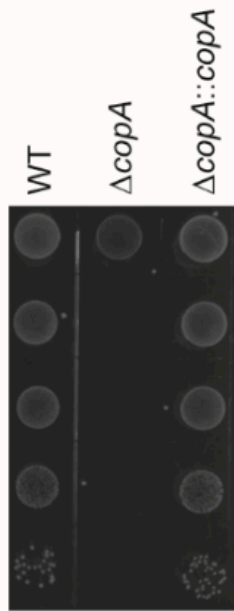

$0.2 \mathrm{mM} \mathrm{Cu}$

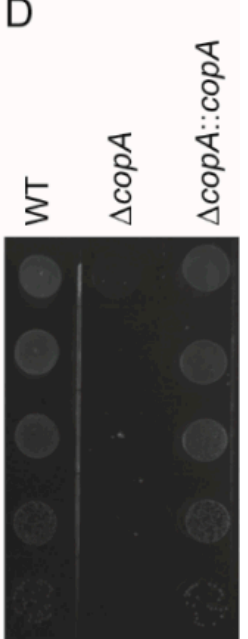

$0.5 \mathrm{mM} \mathrm{Cu}$

Figure 5. CopA is involved in S. suis resistance to copper toxicity in agar plates. Spot dilution assays of the WT, $\triangle \operatorname{cop} A$, and $\triangle \operatorname{cop} A:: \operatorname{cop} A$ strains in the absence (A) and presence of $0.1 \mathrm{mM}(\mathbf{B}), 0.2 \mathrm{mM}(\mathbf{C})$, and $0.5 \mathrm{mM}$ (D) $\mathrm{Cu}$. Overnight cultures of the strains were serially diluted, and $5 \mu \mathrm{L}$ of each dilution was spotted onto the plates from $10^{-1}$ (top) to $10^{-5}$ (bottom). The graphs are representative of three independent experiments.

To determine whether $\mathrm{Cu}$ is bactericidal or bacteriostatic and to further assess the role of CopA in $\mathrm{Cu}$ resistance, the WT, $\triangle \operatorname{cop} A$, and $\triangle \operatorname{cop} A:: \operatorname{cop} A$ strains grown to an $\mathrm{OD}_{600}$ of 0.6 were treated with $\mathrm{H}_{2} \mathrm{O}$ or various concentrations of $\mathrm{Cu}$, and bacterial survival was analyzed by spot dilution assays. After treatment with $\mathrm{Cu}$ for $2 \mathrm{~h}, \triangle \operatorname{cop} A$ formed a smaller number of colonies than did the WT and $\triangle \operatorname{cop} A:$ :copA strains (Figure 6A). The effect was more prominent after $3 \mathrm{~h}$ of treatment (Figure 6B). In contrast, the three strains formed a similar number of colonies following treatment with $\mathrm{H}_{2} \mathrm{O}$ (Figure 6). Thus, $\mathrm{Cu}$ is bactericidal to $S$. suis, and CopA protects the bacterium against this effect.

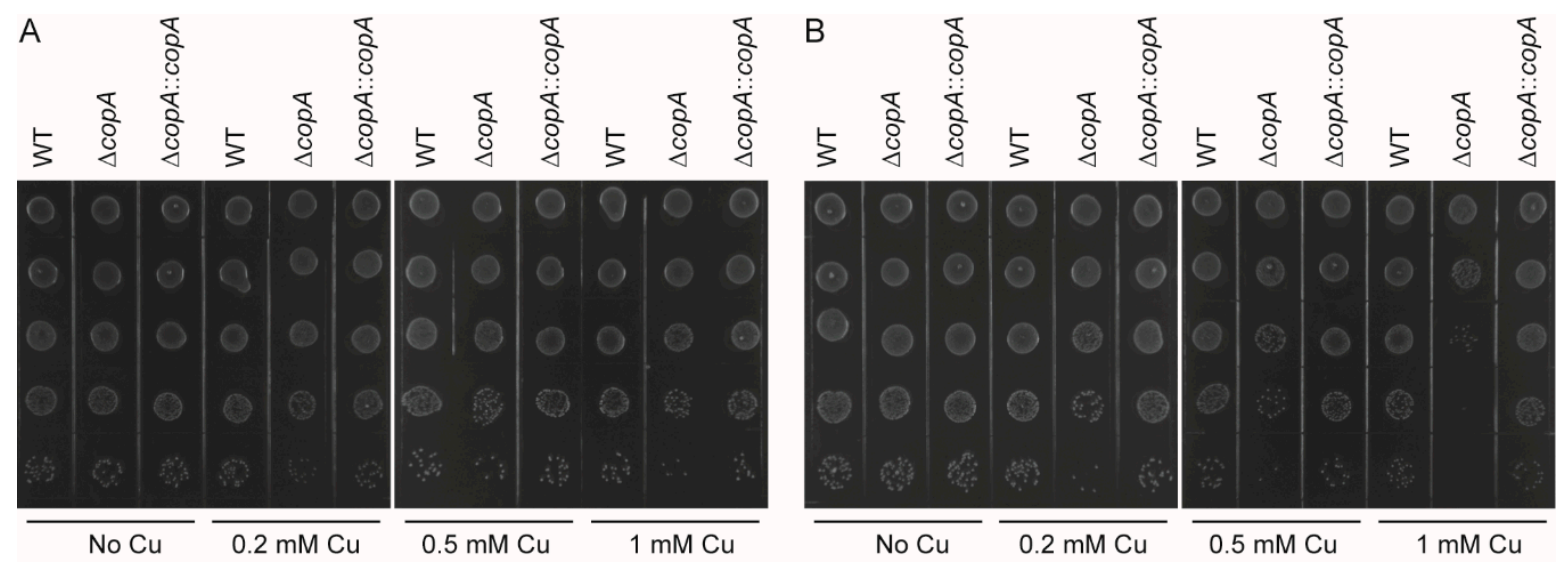

Figure 6. CopA protects $S$. suis against copper-mediated bactericidal effect. The WT, $\Delta \operatorname{cop} A$, and $\triangle \operatorname{cop} A:: \operatorname{cop} A$ strains were grown to an $\mathrm{OD}_{600}$ of 0.6. Each culture was then divided into four equal volumes, which were treated with either varying concentrations of $\mathrm{Cu}(0.2,0.5$, and $1 \mathrm{mM})$ or deionized $\mathrm{H}_{2} \mathrm{O}$. At $2 \mathrm{~h}(\mathbf{A})$ and $3 \mathrm{~h}(\mathbf{B})$, aliquots were removed, serially diluted 10 -fold up to $10^{-5}$ dilution, and $5 \mu \mathrm{L}$ of each dilution was then spotted onto the plates from $10^{-1}$ (top) to $10^{-5}$ (bottom). The graphs are representative of three independent experiments.

We also investigated the role of CopA in the bacterial resistance to other metals. As seen in Figure 7, $\Delta c o p A$ displayed no growth inhibition effects in the presence of excess $\mathrm{Co}, \mathrm{Zn}, \mathrm{Fe}(\mathrm{II}), \mathrm{Fe}(\mathrm{III})$, $\mathrm{Mn}$, or Ni. Thus, CopA is specifically required for $\mathrm{Cu}$ resistance in S. suis. 

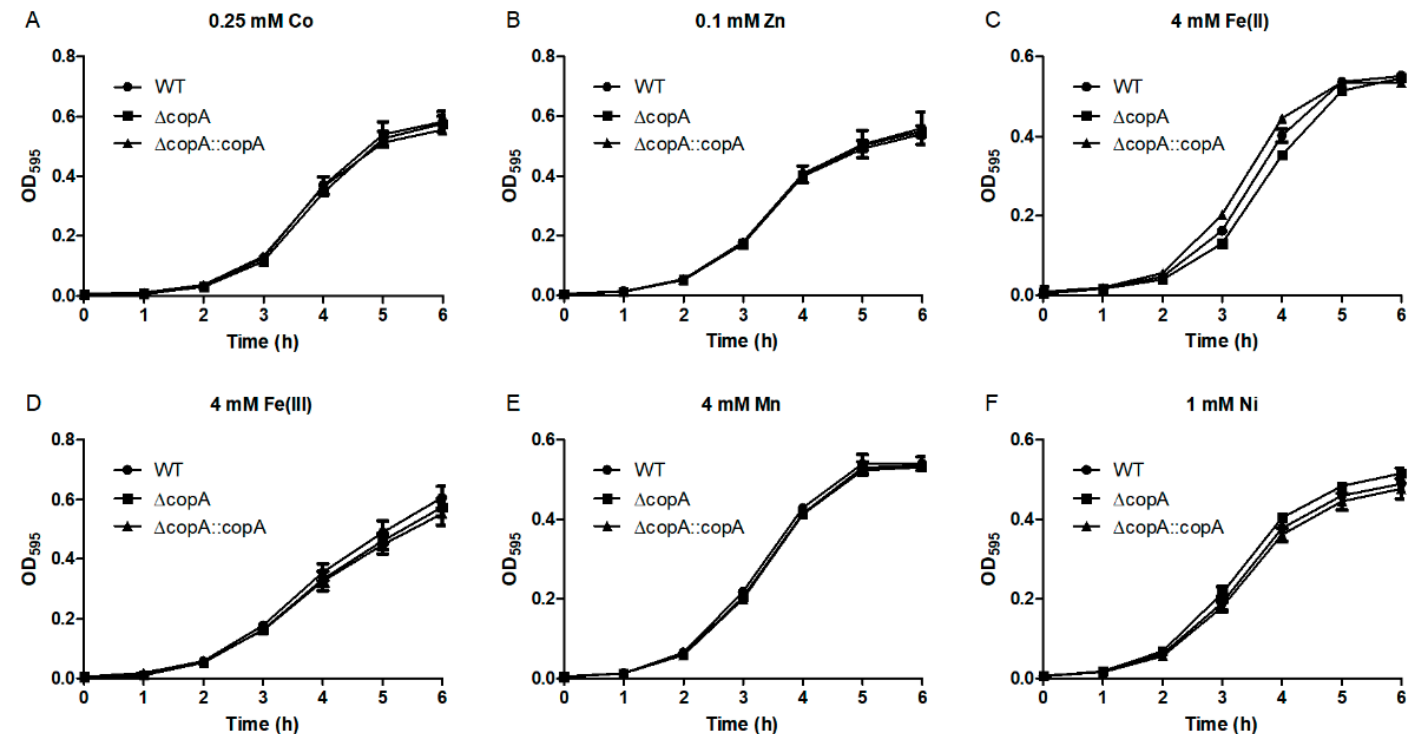

Figure 7. Growth curves of the WT, $\triangle \operatorname{cop} A$, and $\triangle \operatorname{cop} A$ :: copA strains in the presence of various metals. 0.25 mM Co (A); 0.1 mM Zn (B); 4 mM Fe(II) (C); 4 mM Fe(III) (D); 4 mM Mn (E); 1 mM Ni (F).

Taken together, these results indicate that CopA plays an essential role in S. suis resistance to the $\mathrm{Cu}$-induced bactericidal effect.

\section{4. copA Deletion Leads to Increased Intracellular Accumulation of Copper}

To understand the mechanism behind the role of CopA in $\mathrm{Cu}$ resistance, the intracellular $\mathrm{Cu}$ content of the WT, $\triangle \operatorname{cop} A$, and $\triangle \operatorname{cop} A:$ : copA strains grown in the absence or presence of $\mathrm{Cu}$ was determined by inductively coupled plasma-optical emission spectroscopy (ICP-OES). When grown in the absence of $\mathrm{Cu}$, the three strains accumulated low and equivalent levels of intracellular $\mathrm{Cu}$ (Figure 8A). Following the addition of $\mathrm{Cu}$ to the growth medium, a markedly higher level of intracellular $\mathrm{Cu}$ was accumulated in all three strains (Figure 8B). However, the intracellular $\mathrm{Cu}$ content in $\triangle$ copA was significantly higher than that in the $\mathrm{WT}$ and $\triangle \operatorname{cop} A:$ :copA strains (Figure $8 \mathrm{~B})$. These results suggest that the role of CopA in $\mathrm{Cu}$ resistance is mediated by $\mathrm{Cu}$ efflux.

A

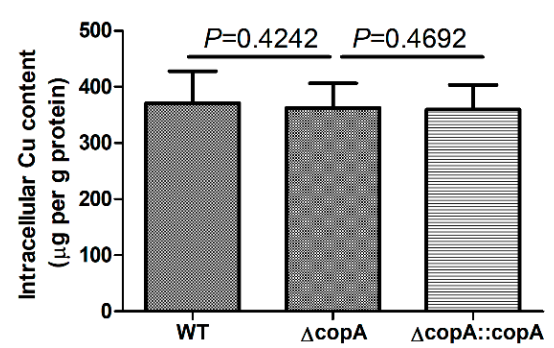

B

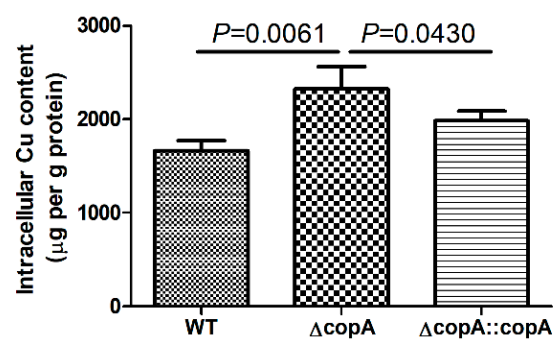

Figure 8. Levels of intracellular copper in the WT, $\triangle \operatorname{cop} A$, and $\triangle \operatorname{cop} A:: \operatorname{cop} A$ strains. The strains were grown to an $\mathrm{OD}_{600}$ of 0.3 , and then treated with either $\mathrm{H}_{2} \mathrm{O}(\mathbf{A})$ or $0.05 \mathrm{mM} \mathrm{Cu}(\mathbf{B})$ for 2 $\mathrm{h}$. The intracellular copper content was analyzed by inductively coupled plasma-optical emission spectroscopy (ICP-OES). Results represent the means and SD from three biological replicates.

\section{Discussion}

The present work focused on evaluating the role of CopA in S. suis resistance to Cu stress. Our data clearly demonstrated that CopA protects $S$. suis against $\mathrm{Cu}$ toxicity, as based on the following lines of evidence: (i) S. suis CopA shares a high level of identity (approximately 50\%) with its homologues from other streptococcal species, all of which are involved in Cu export [17-21]; (ii) S. suis upregulates copA 
expression in response to $\mathrm{Cu}$; (iii) the $\triangle c o p A$ mutant exhibits increased sensitivity to $\mathrm{Cu}$ stress both in liquid media and on agar plates; (iv) the $\triangle \operatorname{cop} A$ mutant forms less colonies after treatment with $\mathrm{Cu}$; and (v) addition of $\mathrm{Cu}$ to the medium leads to a higher level of intracellular $\mathrm{Cu}$ in the $\triangle$ cop $A$ mutant.

Generally, streptococcal species possess a Cu-responsive operon which participates in $\mathrm{Cu}$ resistance [17-21]. Although the genes (i.e. $\operatorname{cop} Y, \operatorname{cop} A$, and $\operatorname{copZ}$ ) that constitute an operon in other species are present in the genome of $S$. suis, they are not arranged into an operon. It has been well established that CopA contributes to $\mathrm{Cu}$ resistance in a number of bacteria and archaea, such as S. pyogenes [21], Neisseria gonorrhoeae [25], Acinetobacter baumannii [26], and Sulfolobus solfataricus [27]. Likewise, CopA is required for $\mathrm{Cu}$ resistance in S. suis. In addition, we showed that treatment with $\mathrm{Cu}$ leads to the significantly decreased survival of the $\triangle \operatorname{cop} A$ mutant, suggesting that $\mathrm{Cu}$ is bactericidal to S. suis. This claim is consistent with observations in N. gonorrhoeae [25] and M. tuberculosis [28].

Cu can catalyze the formation of hydroxyl radicals via the Fenton and Haber-Weiss reactions [12,13]. The oxidative damage caused by hydroxyl radical is an important mechanism underlying $\mathrm{Cu}$ toxicity $[12,13]$. Accordingly, the $\mathrm{Cu}$ efflux system has been demonstrated to be involved in oxidative stress tolerance in several bacteria $[18,26,29]$. However, the deletion of $\operatorname{cop} A$ has been shown to have no effect on S. suis growth under oxidative stress conditions [23]. S. suis possesses multiple regulators and enzymes, such as PerR [30], SpxA1 [22], SrtR [31], superoxide dismutase [32,33], and NADH oxidase [23], to fight against oxidative stress. It is reasonable to speculate that these factors protect $\triangle$ copA against $\mathrm{Cu}$-induced oxidative stress, resulting in the oxidative stress-tolerant phenotype of this mutant.

The involvement of $\mathrm{Cu}$ efflux systems in bacterial pathogenesis has been supported by several lines of evidence. Macrophages use $\mathrm{Cu}$ as a defense mechanism against $M$. tuberculosis infection [14]. Furthermore, bacterial virulence is generally attenuated by deletion of the genes that encode the $\mathrm{Cu}$ efflux systems $[14,20,26]$. However, some $\mathrm{Cu}$ efflux systems are not required for virulence. For example, several periplasmic proteins are required for $\mathrm{Cu}$ tolerance but not for virulence in Vibrio cholerae [34]. Similarly, there is no significant difference in survival times between mice inoculated with the WT strain and those inoculated with the $\triangle \operatorname{cop} A$ mutant [23]. In line with this finding, a recent study showed that $\operatorname{cop} A$ expression was significantly down-regulated during $S$. suis infection of the blood, joint, and heart of piglets [35].

In conclusion, the evidence provided here clearly demonstrates that CopA is involved in $\mathrm{Cu}$ tolerance in S. suis. Moreover, the role of CopA in this resistance to $\mathrm{Cu}$-induced bactericidal effect is mediated by Cu efflux.

\section{Materials and Methods}

\subsection{Bacterial Strains, Plasmids, and Growth Conditions}

The bacterial strains and plasmids used in this study are listed in Table 2. The hypervirulent $S$. suis 2 strain SC19 [36] and its isogenic derivatives were routinely grown at $37^{\circ} \mathrm{C}$ in Tryptic Soy Broth supplemented with 10\% newborn bovine serum (TSBS) or on Tryptic Soy Agar supplemented with $10 \%$ newborn bovine serum (TSAS). Escherichia coli strain DH5 $\alpha$ was cultured at $37^{\circ} \mathrm{C}$ in Luria-Bertani (LB) broth or on LB agar. Spectinomycin was added to the growth medium when required at 50 and $100 \mu \mathrm{g} / \mathrm{mL}$ for E. coli and S. suis, respectively. 
Table 2. Bacterial strains and plasmids used in this study.

\begin{tabular}{|c|c|c|}
\hline Strain or Plasmid & Relevant Characteristics & Source or Reference \\
\hline \multicolumn{3}{|l|}{ Strains } \\
\hline SC19 & Virulent $S$. suis 2 strain isolated from the brain of a dead pig & [36] \\
\hline$\Delta c o p A$ & cop $A$ deletion mutant of strain SC19 & [23] \\
\hline$\triangle \operatorname{cop} A:: \operatorname{cop} A$ & Complemented strain of $\triangle c o p A$ & This study \\
\hline $\mathrm{DH} 5 \alpha$ & Cloning host for recombinant vector & TransGen \\
\hline \multicolumn{3}{|l|}{ Plasmids } \\
\hline pSET4s & Thermosensitive suicide vector; $\mathrm{Spc}^{\mathrm{R} 1}$ & [37] \\
\hline pSET4s::CcopA & pSET4s containing copA and its flanking regions & This study \\
\hline
\end{tabular}

\subsection{Bioinformatic Analysis}

Clustal Omega (https://www.ebi.ac.uk/Tools/msa/clustalo/) was used for the sequence alignment of S. suis CopA with its homologous proteins. The result was further processed with ESPript 3.0 (http://espript.ibcp.fr/ESPript/ESPript/). Homology modelling of $S$. suis CopA structure was performed with SWISS-MODEL (https://www.swissmodel.expasy.org/). The presence of the copA gene in various S. suis strains was detected using blastn searches on the NCBI website.

\section{3. copA Expression Analysis}

S. suis 2 strain SC19 was first grown in TSBS to an $\mathrm{OD}_{600}$ of 0.6 . The culture was then divided into eight equal parts, seven of which were supplemented with $0.5 \mathrm{mM} \mathrm{CuSO}_{4}, 0.25 \mathrm{mM} \mathrm{CoSO}_{4}$, $0.1 \mathrm{mM} \mathrm{ZnSO} 4,1 \mathrm{mM} \mathrm{FeSO}, 1 \mathrm{mM} \mathrm{Fe}\left(\mathrm{NO}_{3}\right)_{3}, 1 \mathrm{mM} \mathrm{MnSO}_{4}$, or $1 \mathrm{mM} \mathrm{NiSO}_{4}$, respectively. Deionized water $\left(\mathrm{H}_{2} \mathrm{O}\right)$ was added to the remaining part, which served as the control. These cultures were further incubated for $15 \mathrm{~min}$, following which the bacterial cells were collected for RNA extraction. Total RNA was isolated using the Eastep Super Total RNA Isolation Kit (Promega, Shanghai, China). The RNA integrity was examined by agarose gel electrophoresis, and the RNA concentration was determined using a NanoDrop spectrophotometer. cDNA was generated from $500 \mathrm{ng}$ of RNA using the PrimeScript RT Reagent Kit with gDNA Eraser (TaKaRa, Dalian, China). Quantitative PCR was performed using TB Green Premix Ex Taq II (TaKaRa, Dalian, China) and the primer pair QcopA1/QcopA2 (Table 3) on the StepOnePlus Real-Time PCR System (Applied Biosystems, Waltham, MA, USA). The levels of copA expression were calculated using the $2^{-\triangle \Delta C T}$ method [38], with $16 \mathrm{~S}$ rRNA as the reference gene. The differences in gene expression were analyzed using one-way analysis of variance with Bonferroni's post-test.

Table 3. Primers used in this study.

\begin{tabular}{|c|c|c|c|}
\hline Primer & Sequence $\left(5^{\prime}-3^{\prime}\right)^{1}$ & Size (bp) & Target Gene \\
\hline QcopA1 & AGAGGATAGGGATGAGCAAGATAACT & \multirow{2}{*}{148} & \multirow{2}{*}{ an internal region of $\operatorname{cop} A$} \\
\hline QcopA2 & TTTGTCTGGTCAGCAGCATTTACT & & \\
\hline Q16S1 & TAGTCCACGCCGTAAACGATG & \multirow{2}{*}{159} & \multirow{2}{*}{ an internal region of $16 \mathrm{~S}$ rRNA } \\
\hline Q16S2 & TAAACCACATGCTCCACCGC & & \\
\hline L1 & CCCCGTCGACAATGAGGGCCAAAACGTC & \multirow{2}{*}{3758} & \multirow{2}{*}{$\operatorname{cop} A$ and its flanking regions } \\
\hline $\mathrm{R} 2$ & CGCCGAATTCACCATCGACCAGCACTGAG & & \\
\hline In1 & TATCACCGAAAGACCACGAC & \multirow{2}{*}{629} & \multirow{2}{*}{ an internal region of $\operatorname{cop} A$} \\
\hline In2 & ATAATGTTTTTGGCGGCAC & & \\
\hline Out1 & GAGGACAAAATCAGGGGCT & \multirow{2}{*}{$2769 / 378$} & \multirow{2}{*}{ a fragment containing $\operatorname{cop} A$} \\
\hline Out2 & AGGGAACAGGCTGAAAACC & & \\
\hline
\end{tabular}

${ }^{1}$ The bold sequences are restriction sites.

\subsection{Construction of the Complementation Strain}

The copA gene and its flanking regions were amplified from the $S$. suis genome using the primer pair L1/R2 (Table 3). After digestion with the Sal I and EcoR I enzymes, the PCR fragment was cloned into pSET4s [37], yielding the pSET4s::CcopA plasmid, which was then electroporated into the 
$\triangle c o p A$ mutant [23]. The same procedures used for mutant construction were followed to create the complementation strain $(\triangle \operatorname{cop} A:: \operatorname{cop} A)$.

\subsection{Growth Curve Analyses}

Growth curve analyses of the WT, $\triangle \operatorname{cop} A$, and $\triangle \operatorname{cop} A:: \operatorname{cop} A$ strains were performed using various concentrations of $\mathrm{CuSO}_{4}, \mathrm{CoSO}_{4}, \mathrm{ZnSO}_{4}, \mathrm{FeSO}_{4}, \mathrm{Fe}\left(\mathrm{NO}_{3}\right)_{3}, \mathrm{MnSO}_{4}$, or $\mathrm{NiSO}_{4}$. Overnight cultures of the strains were diluted 1:100 in TSBS supplemented with various amounts of the individual metals. In the case of $\mathrm{FeSO}_{4}$, trisodium citrate dihydrate was also added to the medium at a concentration of $1 \mathrm{~g} / \mathrm{L}$ to reduce iron precipitation. The strains were grown at $37^{\circ} \mathrm{C}$ in 96 -well plates $(200 \mu \mathrm{L} /$ well), and the $\mathrm{OD}_{595}$ values were measured hourly using a CMax Plus plate reader (Molecular Devices, San Jose, CA, USA).

\subsection{Spot Dilution Assays}

Overnight cultures of the WT, $\triangle \operatorname{cop} A$, and $\triangle \operatorname{cop} A:: \operatorname{cop} A$ strains were serially diluted 10 -fold up to $10^{-5}$ dilution, and $5 \mu \mathrm{L}$ of each dilution was then spotted onto TSAS plates supplemented with varying concentrations of $\mathrm{CuSO}_{4}(0,0.1,0.2$, and $0.5 \mathrm{mM})$. The plates were incubated at $37^{\circ} \mathrm{C}$ for $18 \mathrm{~h}$ and then photographically documented.

In another assay, overnight cultures of the WT, $\triangle \operatorname{cop} A$, and $\triangle \operatorname{cop} A:: \operatorname{cop} A$ strains were diluted 1:100 in TSBS and grown to an $\mathrm{OD}_{600}$ of 0.6. Each culture was then divided into four equal volumes that were treated with either deionized $\mathrm{H}_{2} \mathrm{O}$ or varying concentrations of $\mathrm{CuSO}_{4}(0.2,0.5$, and $1 \mathrm{mM})$. At 2 and $3 \mathrm{~h}$, aliquots of the cultures were serially diluted 10 -fold up to $10^{-5}$ dilution, and $5 \mu \mathrm{L}$ of each dilution was then spotted onto TSAS plates. The plates were incubated at $37^{\circ} \mathrm{C}$ for $18 \mathrm{~h}$ and then photographically documented.

\subsection{Intracellular Copper Content Analysis}

The WT, $\triangle$ copA, and $\triangle \operatorname{cop} A::$ copA strains were grown in TSBS to an $\mathrm{OD}_{600}$ of 0.3 . Each culture was then divided into two equal volumes, which were treated with either deionized $\mathrm{H}_{2} \mathrm{O}$ or $0.05 \mathrm{mM}$ $\mathrm{CuSO}_{4}$ for $2 \mathrm{~h}$. The cells were harvested and washed three times with phosphate buffered saline (PBS) containing 0.25 M EDTA followed by three times with PBS. The cells were resuspended in $350 \mu \mathrm{L}$ of PBS, and part of the suspension was used to measure the total protein content with a Bradford Protein Assay Kit (Sangon Biotech, Shanghai, China). The remaining $300 \mu \mathrm{L}$ of the suspension was centrifuged, following which the cells were resuspended in $66 \%$ nitric acid and digested for $48 \mathrm{~h}$ at $70{ }^{\circ} \mathrm{C}$. Next, the samples were diluted to $2 \%$ nitric acid and analyzed for $\mathrm{Cu}$ content by ICP-OES at Yangzhou University. The differences in intracellular $\mathrm{Cu}$ content were analyzed using the one-tailed unpaired $t$-test.

Author Contributions: C.Z. and M.J. conceived and designed the experiments; C.Z., M.J., T.L., M.G., and L.L. performed the experiments and analyzed the data; C.Z. wrote the paper. All authors read and approved the final manuscript.

Funding: This research was funded by the National Natural Science Foundation of China (no. 31802210), China Postdoctoral Science Foundation (2018M630615), the Natural Science Foundation of the Jiangsu Higher Education Institutions of China (18KJB230007), and the Open Project of State Key Laboratory of Agricultural Microbiology (AMLKF201804).

Acknowledgments: We are grateful to Sekizaki (National Institute of Animal Health, Japan) for supplying plasmid pSET4s.

Conflicts of Interest: The authors declare no conflict of interest. 


\section{Abbreviations}

$\begin{array}{ll}\text { WT } & \text { wild-type } \\ \text { ICP-OES } & \text { inductively coupled plasma-optical emission spectroscopy } \\ \text { TSBS } & \text { Tryptic Soy Broth supplemented with } 10 \% \text { newborn bovine serum } \\ \text { TSAS } & \text { Tryptic Soy Agar supplemented with } 10 \% \text { newborn bovine serum } \\ \text { PBS } & \text { phosphate buffered saline }\end{array}$

\section{References}

1. Lun, Z.R.; Wang, Q.P.; Chen, X.G.; Li, A.X.; Zhu, X.Q. Streptococcus suis: An emerging zoonotic pathogen. Lancet. Infect. Dis. 2007, 7, 201-209. [CrossRef]

2. Wertheim, H.F.; Nghia, H.D.; Taylor, W.; Schultsz, C. Streptococcus suis: An emerging human pathogen. Clin. Infect. Dis. 2009, 48, 617-625. [CrossRef] [PubMed]

3. Segura, M.; Zheng, H.; de Greeff, A.; Gao, G.F.; Grenier, D.; Jiang, Y.; Lu, C.; Maskell, D.; Oishi, K.; Okura, M.; et al. Latest developments on Streptococcus suis: An emerging zoonotic pathogen: Part 1. Future Microbiol. 2014, 9, 441-444. [CrossRef] [PubMed]

4. Higgins, R.; Gottschalk, M.; Boudreau, M.; Lebrun, A.; Henrichsen, J. Description of six new capsular types (29-34) of Streptococcus suis. J. Vet. Diagn Invest. 1995, 7, 405-406. [CrossRef] [PubMed]

5. Hill, J.E.; Gottschalk, M.; Brousseau, R.; Harel, J.; Hemmingsen, S.M.; Goh, S.H. Biochemical analysis, cpn60 and 16S rDNA sequence data indicate that Streptococcus suis serotypes 32 and 34, isolated from pigs, are Streptococcus orisratti. Vet. Microbiol. 2005, 107, 63-69. [CrossRef]

6. Le, H.T.T.; Nishibori, T.; Nishitani, Y.; Nomoto, R.; Osawa, R. Reappraisal of the taxonomy of Streptococcus suis serotypes 20, 22, 26, and 33 based on DNA-DNA homology and sodA and recN phylogenies. Vet. Microbiol. 2013, 162, 842-849.

7. Nomoto, R.; Maruyama, F.; Ishida, S.; Tohya, M.; Sekizaki, T.; Osawa, R. Reappraisal of the taxonomy of Streptococcus suis serotypes 20, 22 and 26: Streptococcus parasuis sp nov. Int. J. Syst. Evol. Micr. 2015, 65, 438-443. [CrossRef]

8. Tohya, M.; Arai, S.; Tomida, J.; Watanabe, T.; Kawamura, Y.; Katsumi, M.; Ushimizu, M.; Ishida-Kuroki, K.; Yoshizumi, M.; Uzawa, Y.; et al. Defining the taxonomic status of Streptococcus suis serotype 33: The proposal for Streptococcus ruminantium sp nov. Int. J. Syst. Evol. Micr. 2017, 67, 3660-3665. [CrossRef]

9. Feng, Y.; Zhang, H.; Wu, Z.; Wang, S.; Cao, M.; Hu, D.; Wang, C. Streptococcus suis infection: An emerging/reemerging challenge of bacterial infectious diseases? Virulence 2014, 5, 477-497. [CrossRef]

10. Goyette-Desjardins, G.; Auger, J.P.; Xu, J.; Segura, M.; Gottschalk, M. Streptococcus suis, an important pig pathogen and emerging zoonotic agent-an update on the worldwide distribution based on serotyping and sequence typing. Emerg. Microbes Infect. 2014, 3, e45. [CrossRef]

11. Samanovic, M.I.; Ding, C.; Thiele, D.J.; Darwin, K.H. Copper in Microbial Pathogenesis: Meddling with the Metal. Cell Host Microbe 2012, 11, 106-115. [CrossRef] [PubMed]

12. Hodgkinson, V.; Petris, M.J. Copper Homeostasis at the Host-Pathogen Interface. J. Biol. Chem. 2012, 287, 13549-13555. [CrossRef] [PubMed]

13. Ladomersky, E.; Petris, M.J. Copper tolerance and virulence in bacteria. Metallomics 2015, 7, 957-964. [CrossRef] [PubMed]

14. Wolschendorf, F.; Ackart, D.; Shrestha, T.B.; Hascall-Dove, L.; Nolan, S.; Lamichhane, G.; Wang, Y.; Bossmann, S.H.; Basaraba, R.J.; Niederweis, M. Copper resistance is essential for virulence of Mycobacterium tuberculosis. Proc. Natl. Acad. Sci USA 2011, 108, 1621-1626. [CrossRef] [PubMed]

15. Begg, S.L. The role of metal ions in the virulence and viability of bacterial pathogens. Biochem. Soc. Trans. 2019, 47, 77-87. [CrossRef] [PubMed]

16. Solioz, M.; Abicht, H.K.; Mermod, M.; Mancini, S. Response of gram-positive bacteria to copper stress. J. Biol. Inorg. Chem. 2010, 15, 3-14. [CrossRef] [PubMed]

17. Vats, N.; Lee, S.F. Characterization of a copper-transport operon, copYAZ, from Streptococcus mutans. Microbiology 2001, 147, 653-662. [CrossRef]

18. Singh, K.; Senadheera, D.B.; Levesque, C.M.; Cvitkovitch, D.G. The cop YAZ Operon Functions in Copper Efflux, Biofilm Formation, Genetic Transformation, and Stress Tolerance in Streptococcus mutans. J. Bacteriol. 2015, 197, 2545-2557. [CrossRef] 
19. Mitrakul, K.; Loo, C.Y.; Hughes, C.V.; Ganeshkumar, N. Role of a Streptococcus gordonii copper-transport operon, copYAZ, in biofilm detachment. Oral Microbiol. Immunol. 2004, 19, 395-402. [CrossRef]

20. Shafeeq, S.; Yesilkaya, H.; Kloosterman, T.G.; Narayanan, G.; Wandel, M.; Andrew, P.W.; Kuipers, O.P.; Morrissey, J.A. The cop operon is required for copper homeostasis and contributes to virulence in Streptococcus pneumoniae. Mol. Microbiol. 2011, 81, 1255-1270. [CrossRef]

21. Young, C.A.; Gordon, L.D.; Fang, Z.; Holder, R.C.; Reid, S.D. Copper Tolerance and Characterization of a Copper-Responsive Operon, copYAZ, in an M1T1 Clinical Strain of Streptococcus pyogenes. J. Bacteriol. 2015, 197, 2580-2592. [CrossRef] [PubMed]

22. Zheng, C.; Xu, J.; Li, J.; Hu, L.; Xia, J.; Fan, J.; Guo, W.; Chen, H.; Bei, W. Two Spx regulators modulate stress tolerance and virulence in Streptococcus suis serotype 2. PLoS ONE 2014, 9, e108197. [CrossRef] [PubMed]

23. Zheng, C.; Ren, S.; Xu, J.; Zhao, X.; Shi, G.; Wu, J.; Li, J.; Chen, H.; Bei, W. Contribution of NADH oxidase to oxidative stress tolerance and virulence of Streptococcus suis serotype 2. Virulence 2017, 8, 53-65. [CrossRef] [PubMed]

24. Solioz, M.; Stoyanov, J.V. Copper homeostasis in Enterococcus hirae. FEMS Microbiol Rev. 2003, 27, $183-195$. [CrossRef]

25. Djoko, K.Y.; Franiek, J.A.; Edwards, J.L.; Falsetta, M.L.; Kidd, S.P.; Potter, A.J.; Chen, N.H.; Apicella, M.A.; Jennings, M.P.; McEwan, A.G. Phenotypic characterization of a copA mutant of Neisseria gonorrhoeae identifies a link between copper and nitrosative stress. Infect. Immun. 2012, 80, 1065-1071. [CrossRef] [PubMed]

26. Alquethamy, S.F.; Khorvash, M.; Pederick, V.G.; Whittall, J.J.; Paton, J.C.; Paulsen, I.T.; Hassan, K.A.; McDevitt, C.A.; Eijkelkamp, B.A. The Role of the CopA Copper Efflux System in Acinetobacter baumannii Virulence. Int. J. Mol. Sci 2019, 20, 575. [CrossRef] [PubMed]

27. Vollmecke, C.; Drees, S.L.; Reimann, J.; Albers, S.V.; Lubben, M. The ATPases CopA and CopB both contribute to copper resistance of the thermoacidophilic archaeon Sulfolobus solfataricus. Microbiology 2012, 158, 1622-1633. [CrossRef] [PubMed]

28. Ward, S.K.; Hoye, E.A.; Talaat, A.M. The global responses of Mycobacterium tuberculosis to physiological levels of copper. J. Bacteriol. 2008, 190, 2939-2946. [CrossRef]

29. Lim, S.Y.; Joe, M.H.; Song, S.S.; Lee, M.H.; Foster, J.W.; Park, Y.K.; Choi, S.Y.; Lee, I.S. cuiD is a crucial gene for survival at high copper environment in Salmonella enterica serovar typhimurium. Mol. Cells 2002, 14, 177-184

30. Zhang, T.F.; Ding, Y.; Li, T.T.; Wan, Y.; Li, W.; Chen, H.C.; Zhou, R. A Fur-like protein PerR regulates two oxidative stress response related operons $d p r$ and metQIN in Streptococcus suis. BMC Microbiol. 2012, 12, 85. [CrossRef]

31. Hu, Y.L.; Hu, Q.; Wei, R.; Li, R.C.; Zhao, D.; Ge, M.; Yao, Q.; Yu, X.L. The XRE Family Transcriptional Regulator SrtR in Streptococcus suis Is Involved in Oxidant Tolerance and Virulence. Front. Cell Infect. Microbiol 2019, 8, 452. [CrossRef] [PubMed]

32. Tang, Y.L.; Zhang, X.Y.; Wu, W.; Lu, Z.Y.; Fang, W.H. Inactivation of the sodA gene of Streptococcus suis type 2 encoding superoxide dismutase leads to reduced virulence to mice. Vet. Microbiol. 2012, 158, 360-366. [CrossRef] [PubMed]

33. Fang, L.H.; Shen, H.X.; Tang, Y.L.; Fang, W.H. Superoxide dismutase of Streptococcus suis serotype 2 plays a role in anti-autophagic response by scavenging reactive oxygen species in infected macrophages. Vet. Microbiol. 2015, 176, 328-336. [CrossRef] [PubMed]

34. Marrero, K.; Sanchez, A.; Gonzalez, L.J.; Ledon, T.; Rodriguez-Ulloa, A.; Castellanos-Serra, L.; Perez, C.; Fando, R. Periplasmic proteins encoded by VCA0261-0260 and VC2216 genes together with copA and cueR products are required for copper tolerance but not for virulence in Vibrio cholerae. Microbiology 2012, 158, 2005-2016. [CrossRef] [PubMed]

35. Arenas, J.; Bossers-de Vries, R.; Harders-Westerveen, J.; Buys, H.; Ruuls-van Stalle, L.M.F.; Stockhofe-Zurwieden, N.; Zaccaria, E.; Tommassen, J.; Wells, J.M.; Smith, H.E.; et al. In vivo transcriptomes of Streptococcus suis reveal genes required for niche-specific adaptation and pathogenesis. Virulence 2019, 10, 334-351. [CrossRef] [PubMed]

36. Teng, L.; Dong, X.; Zhou, Y.; Li, Z.; Deng, L.; Chen, H.; Wang, X.; Li, J. Draft Genome Sequence of Hypervirulent and Vaccine Candidate Streptococcus suis Strain SC19. Genome Announc. 2017, 5, e01484-16. [CrossRef] 
37. Takamatsu, D.; Osaki, M.; Sekizaki, T. Thermosensitive suicide vectors for gene replacement in Streptococcus suis. Plasmid 2001, 46, 140-148. [CrossRef] [PubMed]

38. Livak, K.J.; Schmittgen, T.D. Analysis of relative gene expression data using real-time quantitative PCR and the 2(-Delta Delta C(T)) Method. Methods 2001, 25, 402-408. [CrossRef]

(C) 2019 by the authors. Licensee MDPI, Basel, Switzerland. This article is an open access article distributed under the terms and conditions of the Creative Commons Attribution (CC BY) license (http://creativecommons.org/licenses/by/4.0/). 